\title{
Design of Prototype Battery Management System
}

\author{
Dilip R, Akash G, Ashuthosh Bhat U, Agil K, Tej Raju K
}

\begin{abstract}
The electrical Vehicle (EV) is already on the roadmap of each necessary automaker and is seen because the answer to a a lot of property transport system, contributive to a discount of the gas Emissions. the utilization of inexperienced energy is turning into \{increasingly progressively more and a lot of more necessary in today's world. Therefore, electrical vehicles are presently the most effective alternative for the setting in terms of public and private transportation. Lithium-ion batteries are commonly used in electric vehicles, bec ause of their high energy density.

Sadly, lithium-ion batteries are unsafe unless they are run in the Safety Operation space (SOA). Therefore, A battery management system (BMS) should be employed in each metal particle battery, particularly for those employed in electrical vehicles. Thus, it plays a very important role in coming up with the safer electrical Vehicles.
\end{abstract}

Keywords: Battery management system, passive cell equalization, Li-ion batteries, Electric Vehicle.

\section{INTRODUCTION}

The Battery Management System (BMS) is any electronic sy stem that manages a chargeable battery (cell or battery pack) , such as preventing the battery from being in operation outsi de its safe operating space,Watching its condition, conniving secondary information, covering the information, ruling, aut henticating and/or reconciling its surroundings. A battery pack designed along with electric battery management system with associate degree external communication information bus could be a good battery pack. A sensible battery pack should be charged by a sensible charger. battery management system is, in essence, the "me mory" of an electric battery pack; it monitors and records $\mathrm{cr}$ ucial data for the battery's activity and, in addition, protects $\mathrm{t}$ he battery from harm in an extremely large range of operatin g conditions. the one most significant operate that electric battery management system performs is cell protection. In a vehicle,The BMS is an integral part of a posh, rapidly-acting power management system.

\section{OBJECTIVE}

The objectives of this work as follows:

Revised Manuscript Received on April 25, 2020.

* Correspondence Author

Mr. Dilip R*, Assistant professor in Acharya institute of technology Bangalore

Akash G, Bachelor of Engineering, Department of Mechatronics, Acharya Institute of Technology.

Ashuthosh Bhat U, Bachelor of Engineering, Department of Mechatronics, Acharya Institute of Technology.

Agil K, Bachelor of Engineering, Department of Mechatronics, Acharya Institute of Technology.

Tej Raju K, Bachelor of Engineering, Department of Mechatronics, Acharya Institute of Technology.

(C) The Authors. Published by Blue Eyes Intelligence Engineering and Sciences Publication (BEIESP). This is an open access article under the CC BY-NC-ND license (http://creativecommons.org/licenses/by-nc-nd/4.0/)
1.Design a new BMS platform based on integrated circuits a nd microcontrollers available that target fast sampling, high precision, low consumption and low cost.

2. Build an open system that allows the implementation of different charging and balancing algorithms, and that is able to be used with different battery models.

3. Install a fully functional prototype in electric vehicle.

4. Develop the required experimental testing.

\section{PROBLEM DEFINITION}

As Li-ion batteries area unit restricted to current, voltage and temperature. This causes associate imbalance in cells, fulminant discharge and explosion. there's a demand for a system to regulate and increase the life of the batteries. though BMS has several purposeful modules, nowadays Key issues or problems with BMS area unit accurate measur ement of cell voltage, battery status estimate, battery unifor mity and deed, and battery fault diagnosis.

1.Cell voltage measuring the most important problems lie in:(1)The battery packs of electric motor vehicles have sever al serial cells attached and, thus, there are several channels i $\mathrm{n}$ the region where the voltage is supplied.(2)Measuring volt age needs high accuracy (particularly lithium battery).Estima ting the SOC and different battery states imposes high cell v oltage performance requirements.

2.Battery states algorithmic system estimation Battery states include SOC and SOH.

- State of Charge (SOC) Suggests that the magnitude ratio of the remaining battery ch arge and also the complete battery charge while the battery $\mathrm{i}$ s charged completely.
- State
of
Health

This may be a gain statistic for the current battery cell state ( or battery module, or battery system) as opposed to its ideal conditions.

3. Battery uniformity and equalization: The uniformity of the battery refers to the development that while the battery packs are incorporated by batteries of a sim ilar kind and type, there are certain differences between each cell such as voltage, SOC, fade rate of power and energy, in ternal resistance and its rate of change, battery life, self-disc harge rate and its rate of charge in accordance with time.

\section{BATTERY MANAGEMENT SYSTEM}

\section{A. General Introduction}

The main goal of the project is to build a sustainable Battery Management System (BMS) for a Battery Pack, along with a charging system. The Battery Management system comprises of Master and Slave configuration, Master module involves Wi-fi controller and IO

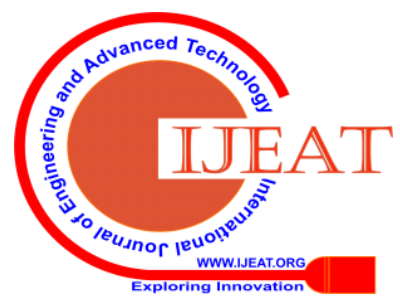




\section{Design of Prototype Battery Management System}

expander to serially communicate with slave modules intermittently. Slave module comprises of controller with capabilities of Temperature sensing and passive cell balancing (PCB). The structure of Master and slave modules is in Figure 1.

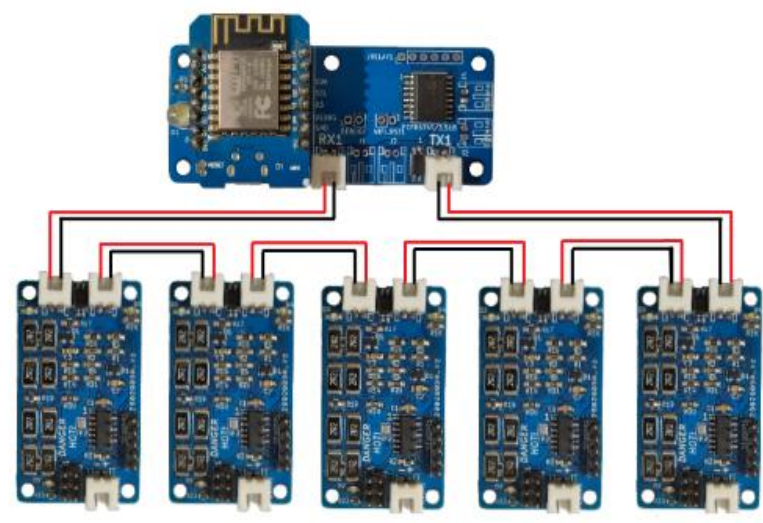

\section{B.Li-ion Battery pack}

Figure 1

The Design of Battery management system focuses mainly on Li-ion technology. Configuration of the battery pack testing as below. Requirement: 21V and 4Ah Battery Pack (5S2P).

\section{Specification of 18650}

- Cell rating: 3.7V 2Ah

- Dimensions:D-18mm, H-65mm

- Mass 45grams

- Maximum discharge current 2A (1C)

- Maximum charging voltage 4.2V

- Maximum charging current $1000 \mathrm{~mA}$

Capacity (mAh):

- Battery pack power $=4 \mathrm{Ah}$ or $4000 \mathrm{mAh}$.

- Individual cell capacity = $2000 \mathrm{mAh}$

- Number of cells needed for parallel connection = $10000 / 2000=5$ nos

Voltage (V):

- The overall nominal voltage of the battery pack is $18.5 \mathrm{~V}$. Nominal voltage of each cell $=3.7 \mathrm{~V}$

- $\quad$ No of cells required for series connection $=18.5 / 3.7$ $=5$ nos

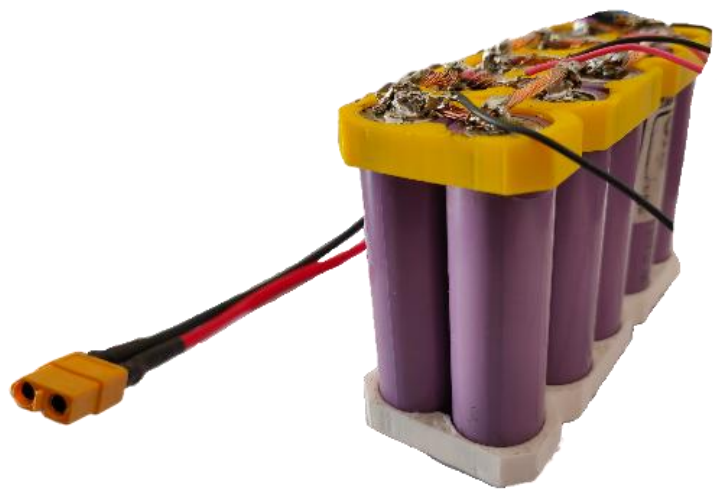

Figure 2

\section{BATTERY MANAGEMENT FEATURES}

The main parameters of Battery Management System (BMS) is Cell Balancing, State of Charge (SOC), Temperature monitoring, over voltage protection. These parameters can be done obtained using different methods. They are explained in following sections.

\section{A. CELL BALANCING.}

- Cell balancing is important parameter where balancing multiple cells with equal amount of charge to reduce risk of failure.

- Cell balancing is done during charging and discharging in electric vehicles for high voltage connected in series configuration instead of several battery packs.

- Cell balancing divided as

1.Passive balancing - excess amount of current will be drained through resister connected across cell, until other cell reaches the same level.

2.Active

balancing-

Excess charge is passed from one cell to the next.

To follow a simplified style, our approach to cell balance, so we consider Passive Cell Balancing technique (KiCAD fig).

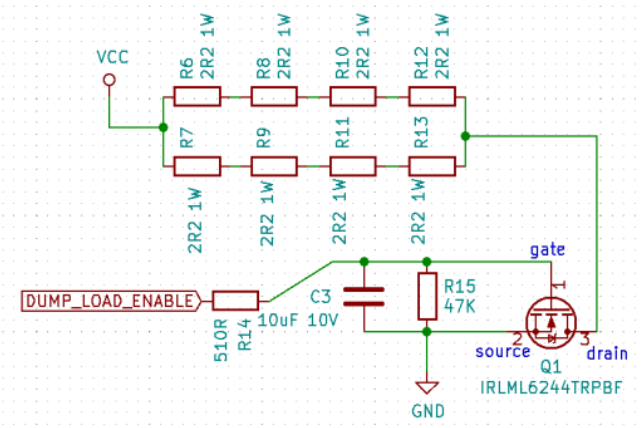

Figure 3

\section{B. TEMPERATURE MONITORING.}

Involves both internal and external temperature control to $\mathrm{m}$ aintain the operating temperature range for efficient battery operation. For precise board temperature, sensor is located near passive cell balancing circuit (KiCAD fig).

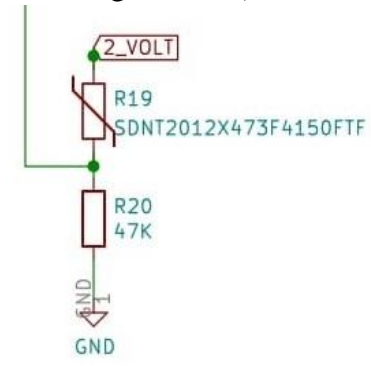

Figure 4

\section{COMMUNICATION AND PROTOCOL}

The slave modules communicate with the slave modules through the I2C communication protocol where the data from the master controller are transferred via the slave modules serially and back to the master module. Rx from the master controller is connected to the Tx of the slave module, and $\mathrm{Rx}$ from master controller is connected in loop manner to rest of the modules. Rx of the last master board is connected back to the Tx of slave board.

\section{USER INTERFACE}

The data from the slave modules are transferred from the master controller wirelessly to a web interface,

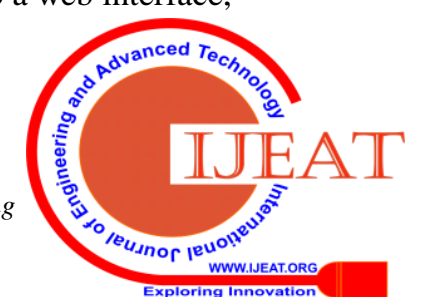


which displays the internal and external temperature along with voltage of the individual cells of the battery. Parameters like Threshold voltage, temperature, and relay conditions can be altered over the web application. Web can be accessed via IP connected to a network.

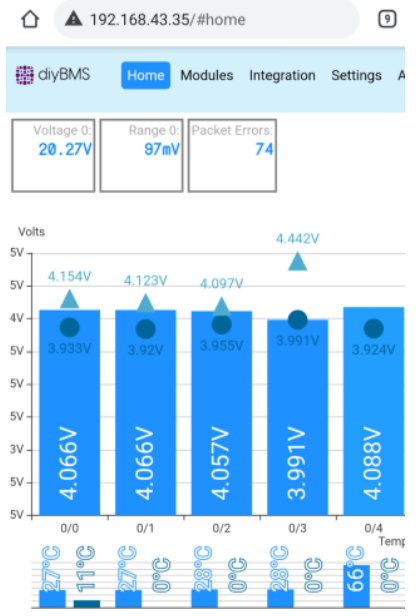

Figure 5

\section{CONSTRUCTION AND WORKING}

a) Setup

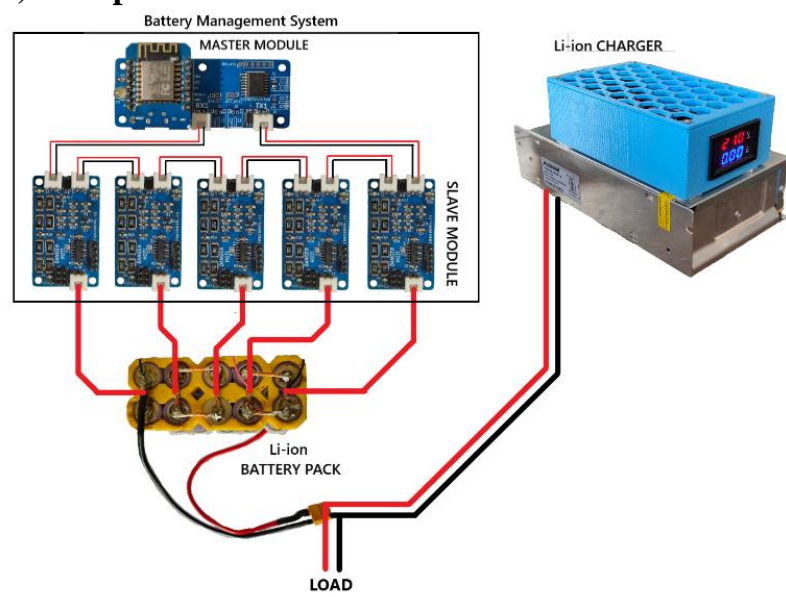

Figure 6

The Master and Slave module are connected in loop manner through I2C for serial monitoring. Master module having Wemos d1 mini requires $5 \mathrm{v}$ power supply in order to connect to a network. The power terminals from slave module are connected to each series of the battery pack of five series that results in maximum voltage of 4.2 volts from each cell. Each cell is provisioned to alter the parameters from the web interface. The bypass temperature of each slave module is denoted to prevent the operation of the board beyond the defined value and the module begins balancing when the temperature is below the bypass value. The charging device is connected to the battery pack termina ls. The battery pack can be charged quickly based on the amperage from the charger supply During the charging/discharging operation, the slave module dumps the excess current through the dump load circuit present in each slave module. The dumping circuit consists of eight resistors that dump $120 \mathrm{~mA}$ each and $1250 \mathrm{~mA}$ in total.

\section{FLOWCHART}

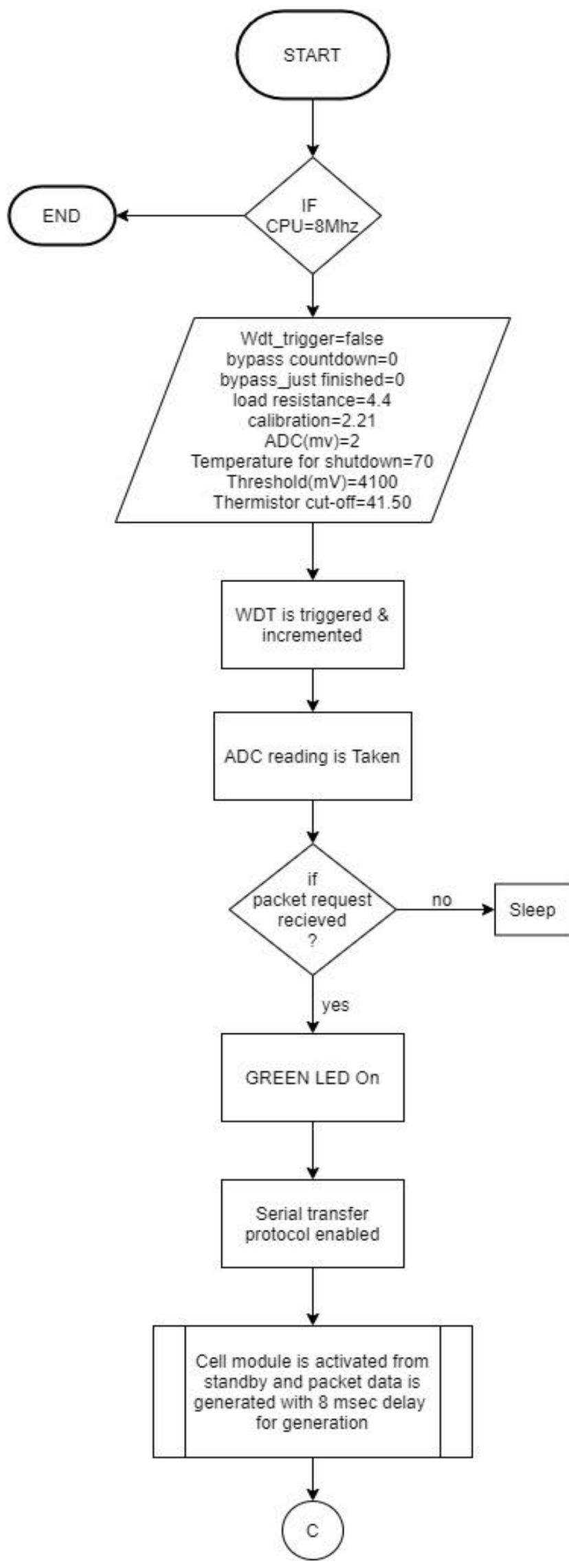




\section{Design of Prototype Battery Management System}
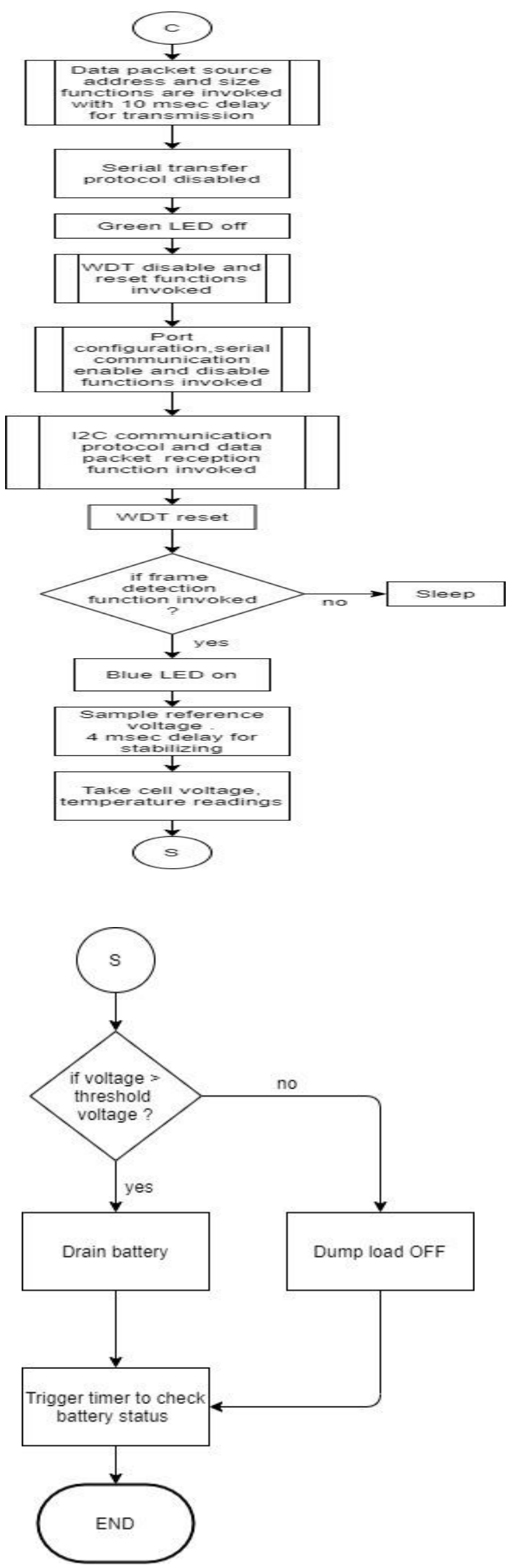

Figure 7

- $\quad$ The module makes sure that the internal clock speed be $8 \mathrm{MHz}$. else, the process will not run.

- The microcontroller is programmed with a watchdog timer (WDT) that is used to time specific tasks.

- $\quad$ The WDT conditions are initialized along with the temperature and voltage thresholds. These values are stored in the EEPROM on power up.

- Watchdog timer is activated when no activity has been recorded for a while. The voltage is sampled by the slave module and then stored in the microcontroller. During the communication, the master controller generates a packet request and transmits it to the slave modules through the I2C communication protocol. Data is generated into a packet by encoding with the COBS algorithm (consistent Overhead byte stuffing). This process is delayed by 8 msecs for packet generation. The green LED signals when the data packet is good for transmission.

- The slave module will receive the framing marker bit to awaken the module from sleep mode. It is then signaled to transmit the data packet along the communication channel. The master controller will handle the errors in the packet if any.

- The communication function is disabled for the efficient operation of the module. The data packets are of 35+bytes and are transmitted at 2400-baud rate. The green LED is at OFF stage.

- $\quad$ During the power up stage, the ports are configured in the modules and the serial communication functions are invoked to check the status of the slave modules.

During the awakening of the slave modules during the awakening from sleep mode, the blue LED glows to signal its activity. The voltage and temperature readings are sampled in every cycle to decide for bypass to be engaged or if the communication fails. A bypass check is initiated to drain the battery by load bypass resistor if over the set point voltage. A counter is also initiated to check the battery at regular intervals and if the battery is below set point voltage, the load resistor circuit is disengaged.

\section{RESULTS AND DISCUSSION}
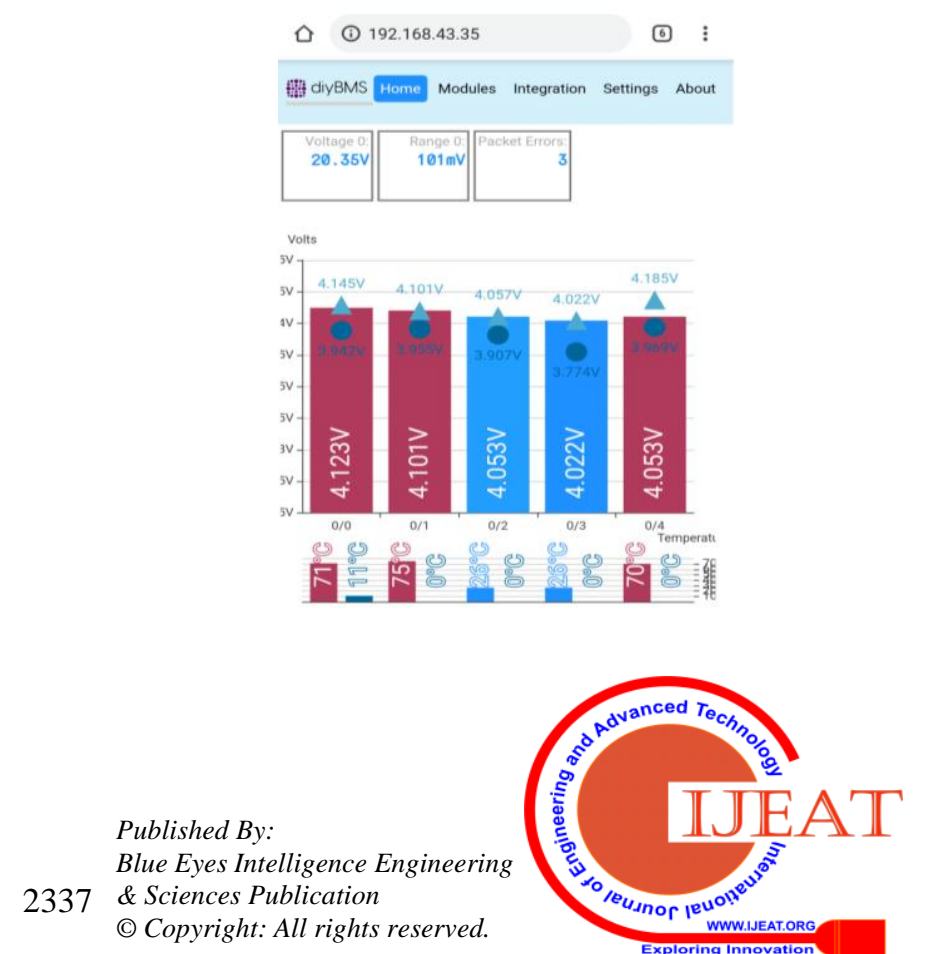


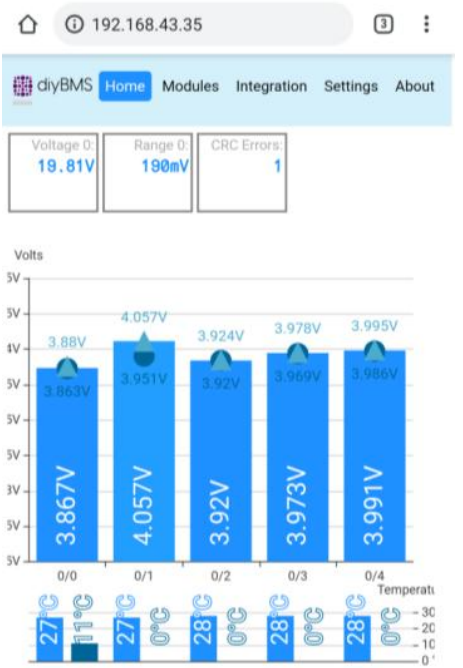

Figure 8- Cells before and after balancing

From the above figure, it is evident that the slave modules enable balancing when the cell voltages are above threshold (in red) and also monitors the temperature internally and externally and displays the total output voltage from the battery pack. The battery pack has been tested multiple times and the results are satisfied.

\section{CONCLUSION}

A workable solution to issues with li-ion batteries has been proposed for an electric vehicle. Overview of particular approach to battery management system hardware and software is provided above work. This work will be adapted to specifications in the future and can be designed for both CAN and wireless communication. The components can also be modified in incremental improvements, optimization, robustness of system.

\section{REFERENCES}

1. Batteries and battery management systems for electric vehicles, March2012

https://www.researchgate.net/publication/229533419 Batteries and battery_management_systems_for_electric_vehicles

2. Research on Li-ion Battery Management System https://ieeexplore.ieee.org/document/5630318

3. Battery management system and control strategy for hybrid and electric vehicle https://www.researchgate.net/publication/224585947_Battery_ management_system_and_control_strategy_for_hybrid_and_ele ctric_vehicle.

4. Wireless Battery Management System of Electric Transport https://www.researchgate.net/publication/320913446 Wireless Battery Management System of Electric Transport.

5. Herrero, V, Ballester, F, Sebastia, A, Mora, F, and Montesinos, J, "The CAN bus:description and operation", Mundo Electronico, Cetisa-Boixareu Editores,Spain,March 2001,pp.44-50.

6. Ecker, M.; Sabet, P.S.; Sauer, D.U. Influence of operational condition on lithium plating for commercial lithium-ion batteries-Electrochemical experiments and post-mortem-analysis. Appl. Energy 2017, 206, 934-946..

7. Texas Instruments. BQ76PL536A-Q1 3 to 6 Series Cell lithium-ion Battery Monitor and Secondary Protection IC for EV \& HEV Applications.2016.Available online: http://www.ti.com/lit/ds/symlink/bq76pl536a-q1.pdf (accessed on 7 January 2018).

8. Santhanagopalan,S.,White,R.E.,"State of charge estimation for electrical vehicle batteries", Proceedings of the IEEE International Conference on Control Applications, Institute of Electrical and Electronics Engineers Inc., New York, NY 10016-5997, United States 2008,pp.690-5.

\section{AUTHORS PROFILE}

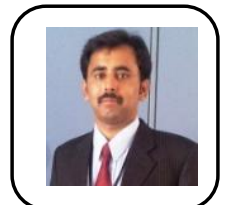

Prof. Dilip R, has received his M.E degree in Control and instrumentation from Bangalore University in the year 2012. He is currently working as Assistant professor in Acharya institute of technology Bangalore. His research interest is in the area of Control System, Signal Conditioning and Process and Control Instrumentation.

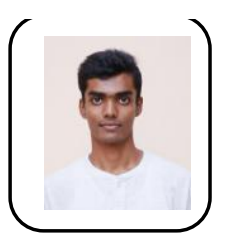

Akash G Bachelor of Engineering, Department of Mechatronics, Acharya Institute of Technology.

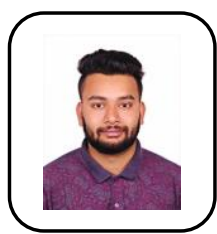

Ashuthosh Bhat U Bachelor of Engineering, Department of Mechatronics, Acharya Institute of Technology.

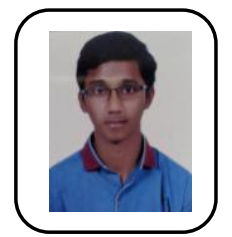

Agil K Bachelor of Engineering, Department of Mechatronics, Acharya Institute of Technology.

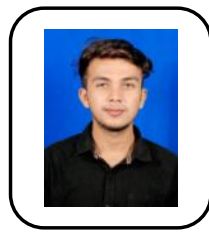

Tej Raju K Bachelor of Engineering, Department of Mechatronics, Acharya Institute of Technology.
Published By:

Blue Eyes Intelligence Engineering \& Sciences Publication (C) Copyright: All rights reserved.

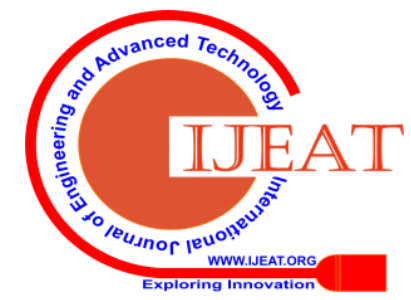

